\title{
Erratum to: Are Endoclips Best Approach to Cannulate an Ampulla Hidden in the Duodenal Diverticulum?
}

\author{
Abdul Nadir ${ }^{1} \cdot$ Keng-Yu Chuang ${ }^{1}$
}

Published online: 23 June 2016

(C) Springer Science+Business Media New York 2016

\section{Erratum to: Dig Dis Sci (2015) 60:1868-1869}

DOI 10.1007/s10620-015-3566-3

The original version of this article contained an error in the author name. The coauthor Dr. Chuang's given name was submitted and published as Kebg-Yu, instead of Keng-Yu. This has been corrected with this erratum.

The online version of the original article can be found under doi:10.1007/s10620-015-3566-3.

Abdul Nadir

anadir786@aol.com

1 Maricopa Medical Center, Phoenix, AZ, USA 